\title{
O ciúme romântico atua como uma profecia autorrealizadora da infidelidade amorosa?'
}

\author{
Does romantic jealousy act as a self-fulfilling \\ prophecy of infidelity to love?
}

Thiago de ALMEIDA²

\begin{abstract}
Resumo
Muitos pesquisadores estudaram os fatores que podem contribuir para que um relacionamento amoroso se mantenha estável e tenha uma boa qualidade para ambos os parceiros. Duas das mais inquietantes preocupações que as pessoas têm no tocante aos relacionamentos amorosos são o ciúme e a infidelidade. O objetivo deste estudo foi verificar se há relação entre os dois fenômenos. Participaram deste estudo 45 casais heterossexuais, com média de idade de 24,6 anos, recrutados por meio de um anúncio colocado no site de uma universidade pública situada na cidade de São Paulo. Para avaliar o grau de ciúme dos participantes utilizou-se uma escala de mensuração para o ciúme romântico. Para avaliar a infidelidade dos participantes utilizou-se o Inventário de Comportamentos Relacionados à Infidelidade, confeccionado especialmente para este trabaIho. Os resultados indicam que: (1) ainda que de forma fraca, o ciúme é um agente de profecia autorrealizadora para a infidelidade $(r=0,25 ; 90 \mathrm{~g}$; $p<0,05)$ e (2) há uma associação para a infidelidade de cada um dos parceiros relacionada à infidelidade do outro parceiro $(r=0,36 ; 45 \mathrm{gl} ; p<0,05)$. Esses resultados indicam, portanto, que há uma relação direta entre o ciúme e a infidelidade.
\end{abstract}

Unitermos: Amor. Ciúme. Relações extramatrimoniais. Infidelidade.

\begin{abstract}
Many researchers have studied the factors that can contribute to a loving relationship remaining stable and being of good quality for both partners. Two of the most worrying concerns that people have with regard to love relationships are jealousy and infidelity. The purpose of this study was to verify whether there is relationship between these two phenomena. Participants in this study were 45 heterosexual couples, with an average age of 24.6 years, recruited through an ad placed on the site of a public university located in the city of São Paulo. To assess the degrees of the participants'jealousy, the "Romantic Jealousy Scale" was used. To evaluate the participants' infidelity, the "Inventory of Infidelity-Related Behaviors", created specifically for this work was used. The results indicated that: (1) even in a low degree, jealousy is an agent of self-fulfilling prophecy for infidelity $(r=0.25,90 \mathrm{df}, p<0.05)$ and (2) there is an association between the infidelity of each partner and the infidelity of the other partner $(r=0.36,45 d f, p<0.05)$. These results, therefore, indicated that there is a direct relationship between the jealousy and infidelity.
\end{abstract}

Uniterms: Love. Jealousy. Extramarital Intercourse. Male famale relationship.

\section{$\boldsymbol{\nabla} \boldsymbol{\nabla} \boldsymbol{\nabla} \boldsymbol{\nabla}$}

1 Apoio: Conselho Nacional de Desenvolvimento Científico e Tecnológico.

2 Universidade de São Paulo, Instituto de Psicologia, Departamento de Psicologia Experimental. R. Dr. Neto de Araújo, 363, Vila Mariana, 04111-001, São Paulo, SP, Brasil. E-mail: <thiagodealmeida@thiagodealmeida.com.br>.

Agradecimentos: A colaboração do Prof. Dr. Paulo Roberto dos Santos Ferreira, da bibliotecária Maria Luiza Lourenço e de Ailton Silva pelas suas sugestões para que este artigo fosse efetivamente publicado. 
"Os amantes que confiam no ciúme para preservar o seu amor, ou são demasiado ingênuos ou são confiantes em demasia"

(Miguel de Cervantes)

O ciúme pode ser entendido como um conjunto de reações frente à ameaça de um rival (real ou não) a um relacionamento importante (Costa, 2005; Kingham \& Gordon, 2004). Está presente com frequência nas relações humanas, e, quando relacionado aos casais, é denominado ciúme romântico (Salovey, 1986; 1989). Hintz (2003) ainda destaca que o ciúme faz parte da relação amorosa. Então, pode-se conceber o ciúme como uma emoção experimentada por um indivíduo que percebe que o amor, a afeição e a atenção do parceiro estão sendo dados a uma terceira parte, quando julga que essas oportunidades deveriam estar sendo oferecidas a ele (Almeida, 2007a; Almeida \& Rodrigues, 2008; Almeida, Rodrigues \& Silva, 2008; Clanton \& Smith, 1998). A ideia de infidelidade, mesmo que não confirmada, sinaliza o ciúme em uma parceria amorosa.

Assim, a expectativa de ser o(a) único(a) na vida do ser amado desaparece quando entra um terceiro elemento na relação. Em alguns casos, o medo da perda origina ideias persecutórias, levando, possivelmente, à destruição da relação, como se a infidelidade tivesse sido consumada. Ademais, segundo muitos autores, como Almeida (2007a; 2007b); Almeida \& Lourenço (2011); Gomes, Amboni \& Almeida (2011); Pires, Abreu, Urbinati, De Tilio \& Almeida (2011); Roveri \& Almeida (2008); Sousa, Santos \& Almeida (2011), o ciúme e a infidelidade são algumas das preocupações mais inquietantes constatadas em pesquisas e na clínica, em uma relação afetivo-sexual. Pode-se dizer que, mesmo quando não se trata da escolha de um(a) namorado(a) com vistas a um relacionamento a longo prazo, as pessoas são temerosas de que seus(suas) parceiros(as) encontrem parceiros(as) potencialmente mais atraentes e gratificantes do que eles(as), e, dessa forma, frequentemente alimentam uma insegurança afetiva (Buss, 2000; Murray \& Holmes, 2000).

Uma das definições mais aceitas para o ciúme é que ele é um "complexo de pensamentos, sentimentos e ações que se seguem às ameaças para a existência ou a qualidade de um relacionamento, sendo estas ameaças geradas pela percepção de uma atração real ou potencial entre um parceiro e um (talvez imaginário) rival" (White, 1981, p.129).
Vale ressaltar que o ciúme romântico está condicionado à ameaça, ainda que virtual, ou mesmo remota, da infidelidade do parceiro. Portanto, é possível imaginar que, devido ao ciúme, as pessoas possam ser, de fato, responsáveis, pela aproximação ou mesmo pelo afastamento dos parceiros amorosos nos relacionamentos que, muitas vezes, querem tanto preservar a qualquer custo.

No que tange à avaliação do ciúme pela literatura científica (Buunk, 1991; Clanton \& Smith, 1998) percebe-se que há a predominância da conceituação do ciúme como uma reação afetiva negativa frente a uma ameaça ao relacionamento amoroso valorizado. O ciúme, portanto, está relacionado à falta de observância do compromisso de exclusividade daqueles que deveriam estar comprometidos com um relacionamento amoroso (Lusterman, 1998). Goldenberg (2006) aponta que, nos tempos atuais, em que os casais não acreditam no amor eterno, é interessante refletir sobre a questão da fidelidade, que permanece como uma busca permanente, inclusive para os relacionamentos extraconjugais. Segundo (Goldenberg, 2006, p. 18)"a fidelidade permanece como um valor, apesar das enormes mudanças nas relações afetivo-sexuais na atualidade". Assim, pode-se inferir que a infidelidade é condenada não somente nos relacionamentos amorosos oficiais, mas também nos relacionamentos paralelos.

A infidelidade pode abarcar muitas manifestações diferentes, além de poder prejudicar inúmeros relacionamentos amorosos, como é o caso do adultério, uma das espécies do gênero infidelidade. Muito embora o adultério tenha sido sempre punido pela sociedade de diversas formas, aos olhos de quem o pratica ele pode se apresentar como uma alternativa válida na busca constante de satisfação.

Muitas vezes, a separação não é cogitada como opção, sobretudo se um dos parceiros apresentar vinculações afetivo-sexuais para com o outro, ou ainda se tal arranjo for interessante para sua vida social, se satisfizer a família, ou se propiciar vantagens profissionais ou econômicas. Uma eventual separação pode implicar elevados custos, materiais e psicológicos, de tal forma que pode ser mais conveniente a permanência no 
relacionamento infiel, dados os ganhos secundários nesse tipo de relação. Por certo, pode-se conjecturar que tanto a fidelidade quanto a infidelidade, por caminhos inversos, operam no sentido de buscar segurança e estabilidade emocional, buscando o(a) parceiro(a), com isso, preencher seu estado de insatisfação afetivo-sexual.

A infidelidade, a exemplo do ciúme, não se atém somente aos relacionamentos maritais, e pode ser encontrada em outros contextos românticos, como namoros, noivados e demais formas de relacionamentos amorosos (Goldenberg, 2006; Shackelford, Leblanc \& Drass, 2000; Thompson, 1983, 1984).

$\mathrm{Na}$ vida real, é sabido que muitos comportamentos são largamente influenciados, e até mesmo governados, por normas e/ou expectativas que funcionam como diretrizes para que as pessoas se comportem de determinada maneira em certa situação. As expectativas sobre os comportamentos podem se transformarem em profecias autorrealizadoras. Essas profecias são crenças que afetam os comportamentos e que, dessa forma, aumentam as chances de ocorrer aquilo em que se crê ou que se teme (Brophy, 1983; Copeland, 1994; Murray, Holmes \& Griffin, 1996).

A questão da profecia autorrealizadora foi inicialmente trazida à atenção dos psicólogos há cerca de um século, em 1911, por meio do célebre caso de Clever Hans, o cavalo do Sr. Von Osten ${ }^{3}$ (Pfungst, 1911). Esse singular equino tornou-se ilustre por ser aparentemente capaz de ler, resolver problemas de harmonia musical, responder a perguntas pessoais, soletrar palavras e resolver problemas aritméticos, apresentando suas respostas através das batidas da pata dianteira no chão. Apesar do ceticismo da época e dos exames por especialistas, sempre o animal demonstrava habilidades impressionantes para um equino. Esse foi um grande dilema a ser resolvido: como um animal aparentemente "irracional" poderia desempenhar habilidades tipicamente humanas?

Um proeminente psicólogo alemão, Oskar Pfungst, imaginou e chefiou sucessivas experiências com o cavalo e descobriu como ele realizava tais proezas. O psicólogo observou que o cavalo era capaz de resolver problemas com ou sem a presença do treinador e que errava muito mais quando não podia ver seu interrogador, ou quando este não sabia a resposta do problema proposto. Assim, pode-se provar que o cavalo estava sendo influenciado por dicas sutis e não intencionais, fornecidas por seus examinadores e pelo público presente, e reagia conforme aquilo que esperavam dele. Essa influência se dava, por exemplo, através das mudanças de comportamentos do público quando uma resposta numérica era esperada: após Ihe formularem uma pergunta, seus expectadores passavam a olhá-lo de forma ininterrupta à espera da resposta correta. À medida que Hans ia completando o número correto de batidas com a pata, os examinadores sutilmente antecipavam com a cabeça ou mesmo com os olhos o momento em que ele completaria a resposta aguardada. Ora, o cavalo tinha sido condicionado a responder a esses movimentos dos observadores como sinais para parar de bater a pata, e isso, geralmente, resultava na resposta correta para a questão formulada. Nisso residia a"inteligência"do animal. Assim,"o caso de Clever Hans demonstra que mesmo as propriedades mais sutis dos estímulos podem sinalizar as conseqüências do responder" (Catania, 1999, p. 40).

Então, seria possível considerar o ciúme romântico como uma profecia autorrealizadora da infidelidade amorosa, similar àquela concebida por Merton (1948), ou por Rosenthal e Jacobson (1968)? Em caso afirmativo, será possível sugerir que o ciúme funciona como uma espécie de profecia autorrealizadora que induziria à perda da qualidade nas relações amorosas, ou mesmo ser um dos principais responsáveis, em fases ulteriores, pela ruptura das mesmas, induzindo os parceiros a se engajarem em comportamentos relacionados à infidelidade?

Embora o ciúme romântico e a infidelidade amorosa sejam dois importantes fenômenos que afetam vários tipos de relacionamentos humanos, ainda não foram totalmente esclarecidos os mecanismos envolvidos na sua gênese, no seu modo de ação e nas consequências que podem acarretar para os desdobramentos amorosos.

Q

3 Osten era um professor de matemática alemão que não tirou nenhum proveito financeiro do talento de seu cavalo, parecendo improvável que tenha tido em mente alguma intenção fraudulenta. 
Esta pesquisa teve como objetivos: (1) verificar se havia uma associação entre os graus de ciúme dos parceiros; (2) verificar se havia uma associação entre ciúme e infidelidade dos parceiros (sexual, emocional ou ambas); (3) verificar se o ciúme poderia atuar como agente de profecia autorrealizadora de infidelidade e (4) identificar se a infidelidade (sexual, emocional ou ambas) de cada um dos parceiros estaria relacionada à infidelidade (sexual, emocional ou ambas) do outro, ambos participantes deste estudo.

\section{Método}

\section{Participantes}

Participaram deste estudo 45 casais heterossexuais, com média de idade de 24,6 anos ( $D P=4,89$; média masculina: 24,3; DP=3,22; média feminina: 24,9, $\mathrm{DP}=6,24)$, recrutados por meio de um anúncio colocado no site de uma universidade situada na cidade de São Paulo. A presente pesquisa foi avaliada e aceita pelo Comitê de Ética Universidade Federal de São Carlos (UFSCar) (Protocolo n 062/04), o qual concedeu parecer favorável para sua realização. A privacidade dos participantes foi mantida em todos os aspectos da pesquisa.

A pesquisa foi realizada em salas de uma universidade situada na capital paulista para aqueles participantes que puderam comparecer para responder aos questionários. Aqueles que não puderam comparecer receberam os questionários e os devolveram por meio de correio eletrônico (e-mail).

\section{Instrumentos}

Escala de Ciúme Romântico (ECR): elaborada por Ramos, Yazawa e Salazar (1994), é constituído por 52 itens. Foram utilizadas as suas duas versões: um questionário com afirmações adequadas para o sexo masculino e o outro para o feminino. A ECR foi formulada para indicar graus de ciúme. Os estudos realizados pelos autores verificaram que os graus de ciúme variam interpessoalmente e intrapessoalmente. As afirmações do questionário são classificadas em quatro categorias: Aceitação (25 itens), Dor (19 itens), Raiva (14 itens) e Não ameaça versus ameaça (40 itens). Cada afirmativa foi acompanhada de uma escala do tipo Likert, com cinco opções de resposta, variando de "discordo totalmente" (alternativa 1) a "concordo totalmente" (alternativa 5).

Nesta pesquisa só foram utilizadas as questões da ECR que compõem o fator geral Não ameaça versus ameaça ${ }^{4}$. Esse fator foi responsável, no estudo original de Ramos (2000), por 13,7\% da variância total das respostas. Seu eigenvalue foi 8,07; e o seu alfa, 0,89. O mesmo conjunto de questões foi utilizado com sucesso em outras pesquisas e, por isso, foi adotado para este estudo. As outras questões do questionário completo não foram utilizadas. As médias das respostas às questões foram classificadas pelo autor em cinco graus crescentes de ciúme: ínfimo, leve, moderado, intenso e excessivo.

Inventário de comportamentos relacionados à infidelidade amorosa: elaborado, especialmente para este trabalho, um instrumento com a finalidade de captar o que as pessoas concebem como comportamentos relacionados à infidelidade (sexual, emocional ou ambas). O instrumento foi constituído por 35 itens, e adequado para quatro versões: uma versão com afirmações adequadas para respondentes masculinos, outra com afirmações adequadas para respondentes femininos, uma para ex-parceiros e outra para atuais parceiros.

Para construir esse questionário, inicialmente foi elaborada uma lista de 30 comportamentos aparentemente relacionados à infidelidade amorosa (sexual, emocional ou ambas). A lista foi construída a partir de citações: (1) ouvidas em atendimentos clínicos realizados pelo primeiro autor, (2) presentes na literatura científica da área e (3) de exemplos citados por uma amostra de 30 voluntários (15 homens e 15 mulheres).

A tarefa da amostra de participantes foi descrever sentimentos, comportamentos e situações que eles consideravam como infidelidade de fato ou potencial. Esses sentimentos, comportamentos e situações po-

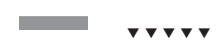

4 Os quarenta itens selecionados que compõem o fator Não ameaça versus ameaça e que foram analisados para esta pesquisa são: 1, 2, 3, 6, 7, 8, 9, 10, 11, 
deriam ter sido vividos pelos próprios respondentes, ou ainda vivenciados por outras pessoas que eles conheciam. Cada respondente foi convidado a apresentar tais descrições por meio das seguintes instruções:

Cite algumas situações, sentimentos e comportamentos que você acha que estariam relacionados a uma infidelidade entre dois namorados. Estas situações descritas podem ter sido vividas por você mesmo, ou ainda, vivenciadas por outras pessoas conhecidas.

Esse procedimento gerou descrições de 30 tipos de comportamentos relacionados à infidelidade amorosa (sexual, emocional ou ambas). Os itens foram submetidos a uma análise semântica por meio do seguinte procedimento: eles foram apresentados a 172 adolescentes (86 homens e 86 mulheres), de uma escola da mesma cidade daqueles que forneceram os 30 itens. A tarefa desses participantes era confirmar ou discordar da hipótese de que cada um dos itens estaria relacionado à infidelidade (sexual, emocional ou ambas), e também citar outros itens, além dos trinta, que achassem relacionados à infidelidade (sexual, emocional ou ambas). Esse procedimento permitiu aperfeiçoar a relação de comportamentos de infidelidade, por meio de ajustes e correções na lista inicial. Um item era eliminado da lista inicial de infidelidade quando pelo menos 50\% das pessoas, de pelo menos um dos gêneros, discordassem que ele estaria relacionado à infidelidade. Por outro lado, um novo item era incluído na lista quando pelo menos duas pessoas o haviam citado. Por meio da utilização desses procedimentos foram excluídas seis das trinta afirmações iniciais, assim como foram acrescentadas outras onze afirmações, perfazendo um total de 35 afirmações que compuseram o instrumento finalizado.

\section{Procedimentos}

A coleta de dados foi organizada em duas etapas: primeira etapa (aplicação pelo pesquisador e aplicação online):

Aplicação pelo pesquisador: medida que os casais de participantes entravam em contato com o experimentador, eram agendadas entrevistas para a coleta de dados. Aqueles que vinham até o local designado foram separados em salas para fazerem a coleta individualmente. Foi distribuída uma carta de apresentação da pesquisa a cada membro do casal e, em seguida, foi-Ihes pedido que lessem e assinassem o Termo de Consentimento Livre e Esclarecido, caso concordassem com os termos assinalados, dessa forma efetivando sua adesão à pesquisa. Então, para cada participante era destinado um conjunto de testes (ECR, Inventário de Comportamentos Relacionados à Infidelidade em Relação aos Ex-Parceiros e Inventário de Comportamentos Relacionados à Infidelidade em Relação aos Atuais Parceiros). Para mitigar possíveis vieses de respostas provocados pela ordem de aplicação das tarefas (efeitos de ordem e efeitos carry over), foi realizado um contrabalanceamento: a distribuição dos dois questionários para cada participante foi realizada de modo alternado, isto é, metade dos participantes respondeu primeiramente à ECR, e a outra metade respondeu primeiramente aos inventários de comportamentos relacionados à infidelidade. Apenas o participante permanecia no local da coleta, o que propiciava uma total privacidade para que ele respondesse aos questionários. Depois da coleta, os participantes receberam uma devolutiva indicando o respectivo grau de ciúme apontado em seu teste ECR.

Aplicação online: coleta de dados daqueles participantes que não puderam comparecer ao local da coleta foi realizada através da rede Internet. Foi pedido a eles que, antes de receber os testes, devolvessem assinado o Termo de Consentimento Livre e Esclarecido que Ihes fora antes enviado por e-mail. Devolvido o Termo de Consentimento, foi-Ihes enviado, por e-mail, o mesmo conjunto de testes aplicados aos participantes que puderam comparecer, com as respectivas instruções. O pesquisador teve o mesmo cuidado de contrabalançar a sequência de encaminhamento dos questionários, para mitigar os possíveis efeitos da ordem de aplicação das tarefas.

Foi dito a todos os participantes que essa era a primeira etapa da pesquisa e que seria desejável, para os objetivos do estudo, que eles também aderissem à segunda etapa, a ser realizada em aproximadamente três meses.

Na segunda etapa, realizada aproximadamente três meses após a primeira, adotou-se mesmo procedimento. 
Os dados da primeira e da segunda etapa da coleta foram tabulados em separado. Para a análise de dados foram utilizadas as seguintes ferramentas estatísticas: média, desvio-padrão, máximo, mínimo, cálculo da correlação de Pearson e o Teste $t$ para comparação de médias. Os softwares utilizados foram o Excel e o Minitab.

\section{Definição das variáveis}

Os dados foram analisados para se verificar a existência de possíveis relações entre as variáveis, sobretudo entre as variáveis ciúme e infidelidade.

Para analisar os dados referentes ao ciúme dos participantes, foi definido como "Ciúme I"o escore obtido na primeira etapa no fator Ameaça versus Não Ameaça do teste ECR, dividido pelo número de itens desse fator. "Ciúme II" foi calculado da mesma forma, com base nos dados obtidos na segunda etapa da pesquisa.

Para analisar os dados referentes à infidelidade amorosa dos participantes da amostra, foi definido como "Infidelidade I" (infidelidade do participante por ocasião da primeira etapa da pesquisa) o escore bruto de comportamentos relacionados à infidelidade de cada um dos participantes dividido pelo tempo de namoro (em meses), declarado na primeira etapa da pesquisa.

Foi definido como "Infidelidade II" (infidelidade do participante por ocasião da segunda etapa da pesquisa) o escore bruto de comportamentos relacionados à infidelidade de cada um dos participantes dividido pelo tempo de namoro (em meses), declarado na segunda etapa da pesquisa.

Foi definido como "Infidelidade III" (infidelidade do parceiro por ocasião da primeira etapa da pesquisa), o escore bruto de comportamentos relacionados à infidelidade dos(as) parceiros(as) de cada um dos participantes, dividido pelo tempo de namoro (em meses), declarado por este na primeira etapa da pesquisa.

Foi definido como "Infidelidade IV" (infidelidade do parceiro por ocasião da segunda etapa desta pesquisa), o escore bruto de comportamentos relacionados à infidelidade dos(as) parceiros(as) de cada um dos participantes dividido pelo tempo de namoro (em meses), declarado por este na segunda etapa da pesquisa.

\section{Resultados}

Foi utilizada a correlação de Pearson para verificar se havia relação entre as duas medidas do "Ciúme"(| e II), entre os tipos de "Infidelidade"(I, II, III e IV) e entre as medidas de Ciúme e os tipos de Infidelidade. Foram obtidas as seguintes correlações:

A correlação entre as variáveis "Ciúme l"e "Ciúme II", independentemente do sexo, foi r=0.87 (90 g/; $p<0.0001)$. Dessa forma, pode-se dizer que há uma tendência para cada participante apresentar o mesmo escore de ciúme nas duas ocasiões (fidedignidade testereteste) (Tabela 1).

Foram, portanto, observadas correlações significativas entre todas as mensurações do ciúme, nas duas etapas da pesquisa. Quanto ao sexo, também não se verificou diferença significativa entre as médias de ciúme mensurado nas duas etapas da pesquisa, conforme aponta o Teste $t$ pareado (Teste $t_{89}=-0,13 ; p=0,898$ ).

Foram calculadas todas as correlações possíveis entre todas as medidas de ciúme (medidas na primeira e segunda etapas da pesquisa, para homens e mulheres) e os quatro tipos de infidelidade (infidelidade dos participantes e dos parceiros, na primeira e na segunda etapa da pesquisa). Dadas as reduzidas dimensões deste artigo, serão apresentadas apenas as correlações estatisticamente significantes: A correlação para o sexo masculino entre as variáveis "Infidelidade I" e "Infidelidade II" foi $r=0,36$ (45gl; $p=0,015$ ); a correlação entre as variáveis "Ciúme I" e "Infidelidade IV", independentemente do gênero, foi $r=0,248$ (90gl; $p=0,018$ ).

Também se pode observar pela presente pesquisa que, ao menos por ocasião da segunda etapa, a infidelidade masculina esteve correlacionada com a

Tabela 1. Correlações entre as medidas de ciúmes mensurados em cada etapa e entre as etapas da pesquisa. São Carlos (SP), 2004

\begin{tabular}{|c|c|c|c|c|c|}
\hline \multirow{2}{*}{\multicolumn{2}{|c|}{$\begin{array}{l}\text { Tipos de ciúme e sexo } \\
\text { dos participantes }\end{array}$}} & \multicolumn{2}{|c|}{ Ciúme I } & \multicolumn{2}{|c|}{ Ciúme II } \\
\hline & & Homens & Mulheres & Homens & 1ulheres \\
\hline \multirow{2}{*}{ Ciúme I } & Homens & $x$ & $0,50^{*}$ & 0,82 & $0,53^{* *}$ \\
\hline & Mulheres & 0,50 & $x$ & 0,46 & 0,91 \\
\hline \multirow{2}{*}{ Ciúme II } & Homens & $0,82^{* * *}$ & $0,46^{* * * *}$ & $x$ & 0,52 \\
\hline & Mulheres & 0,53 & 0,91 & $0,52^{* * * * *}$ & * \\
\hline \multicolumn{6}{|c|}{$\begin{array}{l}{ }^{*} 45 d f ; p<0,001 ;{ }^{* *} 45 d f ; p<0,001 ;{ }^{* * *} 45 d f ; p<0,001 ;{ }^{* * * *} 45 d f ; p<0,001 ; \\
{ }^{* * * * *} 45 \text { l; } p<0,001 \text {. }\end{array}$} \\
\hline
\end{tabular}


infidelidade feminina, ainda que de forma leve $(r=0,364$; $45 d f ; p=0,014)$. Dessa forma, pode-se pensar que alguns daqueles que se engajam em comportamentos de infidelidade estão associados a parceiros(as) que também têm motivações próprias para se engajarem no mesmo tipo de comportamento, bem como há a possibilidade de que parceiros com tendência a trair selecionem outros com a mesma tendência. Outras possíveis causas para a infidelidade mútua seriam a diminuição da veracidade entre os parceiros e a tendência de retaliação.

\section{O ciúme masculino e o ciúme feminino na amostra pesquisada}

Não foram verificadas diferenças significativas entre as médias de ciúme mensurado na primeira e na segunda etapa da pesquisa (Teste t para dados pareados; $\left.t_{89}=-0,13 ; p=0,898\right)$, entre as médias dos participantes do sexo masculino (Teste $t$ para dados pareados; $\left.t_{44}=-1,10 ; 44 \mathrm{gl} ; p=0,279\right)$, nem entre as médias dos participantes do gênero feminino (Teste t para dados pareados; $\left.t_{44}=1,15 ; 44 \mathrm{gl} ; p=0,258\right)$.

\section{Discussão}

O peso que os relacionamentos amorosos assumem na vida das pessoas na contemporaneidade é muito grande, e a vida íntima assume lugar de destaque. Além disso, essa importância geralmente é mais bem percebida quando a relação não é ou não está satisfatória (Nobrega, Fontes \& Paula, 2005). Um dos motivos mais frequentes de desentendimento entre os casais é o ciúme, em seus diversos graus e formas de expressão; outro, a infidelidade. Neste terceiro milênio, muitas questões antigas, como o ciúme e a infidelidade, estão cada vez mais sendo discutidas e reavaliadas pela sociedade, de forma dinâmica. Suas respostas exigem mudanças urgentes nos comportamentos em relação a alguns fenômenos com os quais as pessoas se deparam desde a mais tenra infância.

Quanto à infidelidade amorosa, levanta-se aqui a questão citada por Goldenberg (2006): haveria uma conciliação possível entre a fidelidade e a liberdade? Percebe-se que, a exemplo do ciúme, na infidelidade também há uma distância entre discursos e compor- tamentos, como evidenciada por Goldenberg (2006), em estudo que avaliou a associação entre ciúme e infidelidade, dentre outros fatores que podem acarretar consequências positivas e negativas para os relacionamentos amorosos. Em relação ao ciúme, a pesquisa obteve alta fidedignidade teste-reteste $(r=0,88)$, bem como constatou que parceiros mais ciumentos provavelmente se relacionam com parceiras tão ciumentas quanto eles, ao passo que parceiros pouco ciumentos tendem a atrair parceiras menos ciumentas.

Como as profecias autorrealizadoras são, em resumo, definidas como crenças, em potencial, capazes de exercer influência sobre o outro, de maneira que $B$ se engaje em algum comportamento (ou mesmo mude de atitude) de acordo com o que $A$ deseja e/ou tem por meta (Copeland, 1994; Murray, Holmes \& Griffin, 1996), pode-se considerar o ciúme como uma profecia autorrealizadora, nos moldes concebidos por Rosenthal e Jacobson (1968), ou mesmo Merton (1948). Em outras palavras, existem algumas situações afetivo-sexuais nas quais se instala insidiosamente um alienante e possessivo ciúme do parceiro, que acaba por interferir e molestar a liberdade do outro companheiro, alvo desse apego exagerado, que pode resultar em elementos de gradual distanciamento do casal. Dessa forma, o temor de perder a pessoa amada faz com que a infidelidade ocupe um lugar destacado no espaço contencioso dos relacionamentos afetivo-sexuais. Sobretudo, na escuta da clínica, observam-se casos nos quais pessoas ciumentas tentam forçar o parceiro a se sacrificar para nivelar a relação, e se assustam com a possibilidade de este(a) encontrar emprego, atividade ou relacionamento que o(a) torne mais confiante e menos dependente (Almeida, Centeville \&Tardivo, 2008). Essas situações podem atuar na motivação separatória de uma mulher que se sente tolhida em sua liberdade pessoal e que não vê mais nenhum sentido em manter uma relação amorosa, desenvolvida em clima de ciúme e desconfiança, recebendo diuturnas críticas sobre seus valores, relações, profissão e planos de crescimento pessoal.

Por meio deste estudo, ainda se pode sugerir uma modesta relação entre as crenças primárias, que fundamentam o ciúme, e o futuro do relacionamento. Como as dúvidas começam a ser hiperdimensionadas e supervalorizadas, a pessoa é impelida a verificar se elas são ou não coerentes com suas expectativas, 
entrando num ciclo delirante de medos e desconfianças. Logo, ainda que sutilmente, o ciumento começa a hostilizar o ser amado, com o objetivo manter a indissolubilidade do vínculo. Assim, mesmo que inconscientemente, passa a tratar o ser amado com rivalidade. Essa atitude, muitas vezes, não é identificada como forma de zelo e carinho por parte de quem a manifesta, sobretudo por aqueles que padecem das mais diversas nuanças desse sentimento, por vezes traduzido em violência física ou psicológica (Almeida, 2008; Almeida, Centeville \& Tardivo, 2008; Centeville \& Almeida, 2007). Daí, não fica difícil compreender que, nesse estado de carência, parceiros intimidados, agredidos, seja fisicamente ou em sua autoestima, começam a aprender a escapar dessas relações improdutivas e contam, muitas vezes, com o encanto e o auxílio de uma nova aventura sentimental, que promete nascer destituída de todas as imperfeições do atual relacionamento.

Em outras situações, os relacionamentos de infidelidade podem psicologicamente colaborar para a regulação da estabilidade do casamento - nesse caso, para servirem funcionalmente como uma tentativa de sobreviver ao relacionamento, seja pelo fato de a pessoa ser pouco assertiva e não se colocar diante do parceiro, seja por não se sentir fortalecida para romper o atual relacionamento desgastado pelo ciúme.

Pode-se verificar pela presente pesquisa que os escores de ciúme da primeira etapa estão diretamente correlacionados aos escores da infidelidade da segunda etapa ( $r=0,248 ; 90 \mathrm{gl} ; p=0,018)$. Assim, pode-se concluir que quanto maior o ciúme do(a) participante, maior a chance de ele(a) ser traído(a) pelo parceiro(a), conforme preconizado pela teoria da profecia de autorrealização em relação à infidelidade do outro. Então, as pessoas não seriam imunes aos encontros amorosos interpessoais e também não estariam ilesas às expectativas ciumentas do parceiro. O parceiro teria a propriedade de modelar o comportamento amoroso do outro.

Dessa forma, os resultados desta pesquisa sugerem que o ciúme está associado à infidelidade amorosa do parceiro, tal como predito pela profecia autorrealizadora (Rosenthal \& Jacobson, 1968). Outra hipótese é que aqueles que têm mais ciúmes leram antecipadamente os indícios de propensão do parceiro à infidelidade. É possível, ainda, questionar esses achados, alegando que o instrumento empregado para esta pesquisa poderia ter provocado um efeito reativo.
Segundo esse raciocínio, o pré-teste poderia ter influenciado a sensibilidade, ou ainda a capacidade de induzir um maior grau de vigilância dos parceiros, o que tornaria os participantes mais atentos às infidelidades que estavam em andamento, e isso comprometeria a validade interna do instrumento. Contudo, existem algumas evidências que enfraquecem essa hipótese. Primeiramente, se por um lado o instrumento empregado nesta pesquisa tivesse induzido o comportamento de vigilância nos participantes, por outro lado, provavelmente ele também deveria ter provocado efeito semelhante naqueles que estivessem pensando em trair os parceiros, fazendo-os esconder ainda mais sua infidelidade, ou fazendo-os trair menos. Outra objeção a essa hipótese é que a infidelidade foi relatada pelos próprios perpetradores, de modo que ela não é fruto da percepção do parceiro, e sim, provavelmente, induzida por este.

Foram tomados cuidados para reduzir outros vieses experimentais, tais como o sigilo das informações obtidas, o anonimato dos participantes, a coleta em salas e momentos separados, dentre outras medidas.

\section{Considerações Finais}

O propósito principal do presente estudo foi determinar se havia relação entre os comportamentos de infidelidade e os escores de ciúme. Ao tratar da temática da infidelidade amorosa, muitos direcionam seus olhares para o 'traidor' e vitimizam o 'traído'. Não se pretendeu, com este trabalho, determinar relações de causa e efeito entre essas duas variáveis, ou ainda, arranjar uma justificativa plausível para as traições e, muito menos, deslocar qualquer culpa da infidelidade para o traído, mas sim averiguar as possíveis contribuições de cada uma das partes da díade amorosa na composição da configuração final do quadro da infidelidade.

O comportamento amoroso não parece ser um produto contemporâneo cultural criado por poetas românticos, ao contrário do que algumas pessoas possam pensar. $O$ amor é um sistema complexo de pensamentos, sentimentos e comportamentos que está relacionado com o bem-estar do ser humano e está presente em todas as culturas conhecidas. Instalado e selecionado pela evolução genética está a serviço da manutenção 
da vida e da perpetuação da espécie. Ele constantemente sofreu ameaças relacionadas ao fato de que um dos parceiros possa potencialmente ser atraído por outro. Então, a fim de diminuir as chances do desvio de recursos valiosos por meio da infidelidade, a natureza lançou mão do ciúme romântico como um recurso para ajudar na permanência dos parceiros nos relacionamentos amorosos.

É comum para as pessoas, em algum momento da vida, buscar um parceiro com quem possam compartilhar afetividade, alegria, prazer, companheirismo, sexo, dentre outros aspectos. Acontece que, quando as pessoas aderem a relacionamentos amorosos e essa busca persiste através de traições, esta pode causar grandes prejuízos, muitas vezes para todos os envolvidos e para parentes e amigos que acompanham a situação. Provavelmente por isso, o ciúme romântico tenha sido um mecanismo selecionado positivamente para precaver os relacionamentos amorosos dos malefícios de uma eventual infidelidade.

Consoante a literatura aponta, o ciúme em dose certa serviria para fortalecer, aliado a outros fatores, a estabilidade de um relacionamento amoroso. Há de se ressaltar que uma completa ausência de ciúme é danosa para um relacionamento amoroso, por geralmente implicar uma baixa adesão de pelo menos uma das partes envolvidas. Concorde com essa linha de raciocínio, a psicologia evolutiva majoritariamente concorda que o ciúme pode estimular uma pessoa a acalmar o parceiro, com declarações de fidelidade e ligação, contribuindo para a durabilidade do relacionamento e a satisfação de ambos.

Embora seja possível que esse mecanismo tenha sido selecionado para garantir as parcerias constituídas, muitos dos excessos de ciúme, sobretudo quando relacionados à violência verbal ou física, acabam por complicar, em vez de facilitar os relacionamentos amorosos em andamento. Dessa forma, o ciúme romântico e a infidelidade amorosa não somente são dois importantes temas que afetam vários relacionamentos humanos, bem como um desafio para muitos dos mesmos.

Evidencia-se que, além da profecia autorrealizadora mediada pelo ciúme, existem evidências sobre outras causas da infidelidade, embora não mencionadas no presente estudo.
Pouco ainda se conhece a respeito de quais tipos de parceiros são mais suscetíveis à infidelidade, mas este estudo permitiu identificar e discutir um pouco mais sobre alguns fatores que a promovem. Ao analisar os 35 comportamentos relacionados à infidelidade, este estudo pôde concluir que, como aponta a literatura, homens e mulheres engajam-se em formas de infidelidade que, embora apresentem muitas semelhanças, também apresentam algumas diferenças. As mulheres, sobretudo, quanto mais insatisfeitas com seus parceiros, buscarão aventuras emocionais, enquanto os homens buscarão aventuras de natureza sexual.

O presente estudo contribuiu para uma melhor compreensão da dinâmica interpessoal amorosa, principalmente referente ao ciúme e à infidelidade. Permitiu observar, ainda, que o sexo feminino tende a apresentar menos ciúme que o masculino.

Embora esta pesquisa tenha apresentado evidências de que o ciúme atua, em certa medida, como profecia autorrealizadora da infidelidade, um questionamento ainda permanece presente, levando-se em consideração a subjetividade do tema: qual é a dosagem ideal de ciúme para que as pessoas possam zelar por seus relacionamentos amorosos sem, no entanto, prejudicá-los? como medi-la? quem sente menos ciúme deve atingir a "dose certa"? Esses questionamentos permanecerão para futuras pesquisas.

\section{Referências}

Almeida, T. (2007a). Ciúme romântico e infidelidade amorosa entre paulistanos: incidências e relações. Dissertação de mestrado não-publicada, Instituto de Psicologia, Universidade de São Paulo.

Almeida, T. (2007b). Infidelidade heterossexual e relacionamentos amorosos contemporâneos. Pensando Famílias, 11, 49-56.

Almeida, T. (2008). A violência no namoro. Anais da VI Jornada APOIAR: saúde mental e violência; contribuições no campo da psicologia clínica (pp.136-146). São Paulo.

Almeida, T., Centeville, V., \& Tardivo, L. S. L. P. C. (2008). Propostas psicoterapêuticas para vítimas do ciúme patológico. Anais da VI Jornada APOIAR: saúdemental eviolência; contribuições no campo da psicologia clínica (pp.170-180). São Paulo.

Almeida, T., \& Lourenço, M. L. (2011, jul./dez). Ciúme romântico: um breve histórico, perspectivas, concepções correlatas e seus desdobramentos para os relacionamentos amorosos. Revista de Psicologia, 2 (2), 18-32. 
Almeida, T., \& Rodrigues, K. R. B. (2008). Mitos da infidelidade. Psique, 33, 70-79.

Almeida, T., Rodrigues, K. R. B., \& Silva, A. A. (2008). O ciúme romântico e os relacionamentos amorosos heterossexuais contemporâneos. Estudos de Psicologia (Natal), 13 (1), 83-90.

Brophy, J. (1983). Research on the self-fulfilling prophecy and teacher expectations. Journal of Educational Psychology, 76 (2), 236-247.

Buss, D. (2000). A paixão perigosa: por que o ciúme é tão necessário quanto o amor e o sexo. Rio de Janeiro: Objetiva.

Buunk, B.P. (1991). Jealousy in close relationships: an exchangetheoretical perspective. In P. Salovey (Ed.), The psychology of jealousy and envy (pp.148-177). New York: Guilford Press.

Catania, A. C. (1999). Aprendizagem: comportamento, linguagem e cognição. Porto Alegre: ArtMed Sul.

Centeville, V., \& Almeida, T. (2007). Ciúme romântico e a sua relação com a violência. Psicologia Revista, 16 (1-2), 71-89.

Clanton, G., \& Smith, L. G. (1998). Jealousy. New York: University Press of America.

Copeland, J. T. (1994). Prophecies of power: motivational implications of social power for behavioral confirmation. Journal of Personality and Social Psychology, 67 (2), 264-277.

Costa, N. (2005). Contribuições da psicologia evolutiva e da análise do comportamento acerca do ciúme. Revista Brasileira de Terapia Comportamental e Cognitiva, 7(1), 5-13.

Goldenberg, M. (2006). Infiel: notas de uma antropóloga. Rio de Janeiro: Record

Gomes, A. L., Amboni, G., \& Almeida, T. (2011). Ciúme romântico em casais heterossexuais: relatos de pessoas casadas e unidas consensualmente. Pensando Famílias, 15 (2), 31-50.

Hintz, H. C. (2003). O ciúme no processo amoroso. Pensando Famílias, 5 (5), 45-55.

Kingham, M., \& Gordon, H. (2004). Aspects of morbid jealousy. Advances in Psychiatric Treatment, 10, 207-215.

Lusterman, D. D. (1998). Infidelity: a survival guide. Oakland: New Harbinger Publications.

Merton, R. K. (1948). The self-fulfilling prophecy. Antioch Review, 8, 193-210.

Murray, S. L., \& Holmes, J. G. (2000). Seeing the self through a partner's eyes: why self-doubts turn into relationship insecurities. In A. Tesser \& R. B. Felson (Eds.), Psychological perspectives on self and identity (pp.173-197). Washington, DC: American Psychological Association.

Murray, S. L., Holmes, J. G., \& Griffin, D. W. (2000). Self-esteem and the quest for felt security: how perceived regard regulates attachment processes. Journal of Personality and Social Psychology, 78, 478-498.

Murray, S. L., Holmes, J. G., \& Griffin, D. W. (1996). The self-fulfilling nature of positive illusions in romantic relationships:
Love is not blind, but prescient. Journal of Personality and Social Psychology, 71 (6), 1155-1180.

Nobrega, S. M., Fontes, É. P. G., \& Paula, F. M. S. M. (2005). Do amor e da dor: representações sociais sobre o amor e o sofrimento psíquico. Estudos Psicologia (Campinas), 22 (1), 77-87. doi: 10.1590/S0103-166X2005000100009.

Pfungst, O. (1911). Clever Hans: the horse of Mr. von Osten. Bristol: Thoemmes Press.

Pires, M. R. M., Abreu, M., Urbinati, M. C., Tilio, R., \& Almeida, T. (2011). Representações dos homens heterossexuais acerca do ciúme contemporâneo. Anais do III Simpósio Brasileiro de Família e Desenvolvimento Humano: prevenção, intervenção e promoção da saúde psicológica (pp.123-124). Curitiba, PR.

Ramos, A. L. M. (2000). Ciúme romântico: teoria e medida psicológicas. São Paulo: Stiliano.

Ramos, A. L. M., Yazawa, S. A. K., \& Salazar, A. F. (1994). Desenvolvimento de uma escala de ciúme romântico. Psicologia: Teoria e Pesquisa, 10 (3), 439-451.

Rosenthal, R., \& Jacobson, L. (1968). Pygmalion in the classroom: teacher expectations and pupil's intellectual development. New York: Holt, Rinehart and Winston.

Roveri, P. M., \& Almeida, T. (2008). Ciúme: o inferno do amor possessivo - uma análise sob a perspectiva da tríplice contingência. Anais da VI Jornada APOIAR: saúde mentale violência: contribuições no campo da psicologia clínica (pp.526-542). São Paulo.

Salovey, P. (1986). The differentiation of social-comparison jealousy and romantic jealousy. Journal of Personality and Social Psychology, 50 (6), 1100-1112.

Salovey, P. (1989). Envy and jealousy in close relationships. In C. Hendrick (Ed.), Close relationships: review of personality and social psychology (pp.221-246). Newbury Park: Sage.

Shackelford, T. K., LeBlanc, G. J., \& Drass, E. (2000). Emotional reactions to infidelity. Cognition and Emotion, 14, 643-659.

Sousa, D. L., Santos, R. B. , \& Almeida, T. (2011). Vivências da infidelidade conjugal feminina. Anais do III Simpósio Brasileiro de Famíliae Desenvolvimento Humano: prevenção, intervenção e promoção da saúde psicológica (pp.117-119). Curitiba, PR.

Thompson, A. P. (1983). Extramarital sex: review of the research literature. Journal of Sex Research, 19 (1), 1-22.

Thompson, A. P. (1984). Emotional and sexual components of extramarital relations. Journal of Marriage and the Family, 46 (1), 35-42.

White, G. L. (1981). Some correlates of romantic jealousy. Journal of Personality, 49 (2), 129-147.

Recebido em: 25/11/2010

Versão final em: 28/2/2012

Aprovado em: 13/3/2012 